\title{
Characteristics of aerosol vertical profiles in Tsukuba, Japan, and their impacts on the evolution of the atmospheric boundary layer
}

\author{
Rei Kudo $^{1}$, Toshinori Aoyagi ${ }^{2}$, and Tomoaki Nishizawa ${ }^{3}$ \\ ${ }^{1}$ Meteorological Research Institute, Japan Meteorological Agency, Tsukuba, 305-0052, Japan \\ ${ }^{2}$ Japan Meteorological Agency, Tokyo, 100-8122, Japan \\ ${ }^{3}$ National Institute for Environmental Studies, Tsukuba, 305-0053, Japan
}

Correspondence: Rei Kudo (reikudo@mri-jma.go.jp)

Received: 16 December 2017 - Discussion started: 9 February 2018

Revised: 27 April 2018 - Accepted: 8 May 2018 - Published: 29 May 2018

\begin{abstract}
Vertical profiles of the aerosol physical and optical properties, with a focus on seasonal means and on transport events, were investigated in Tsukuba, Japan, by a synergistic remote sensing method that uses lidar and sky radiometer data. The retrieved aerosol vertical profiles of the springtime mean and five transport events were input to our developed one-dimensional atmospheric model, and the impacts of the aerosol vertical profiles on the evolution of the atmospheric boundary layer (ABL) were studied by numerical sensitivity experiments. The characteristics of the aerosol vertical profiles in Tsukuba are as follows: (1) the retrieval results in the spring showed that aerosol optical thickness at $532 \mathrm{~nm}$ in the free atmosphere (FA) was 0.13 , greater than 0.08 in the ABL owing to the frequent occurrence of transported aerosols in the FA. In other seasons, optical thickness in the FA was almost the same as that in the ABL. (2) The aerosol optical and physical properties in the ABL showed a dependency on the extinction coefficient. With an increase in the extinction coefficient from 0.00 to $0.24 \mathrm{~km}^{-1}$, the Ångström exponent increased from 0.0 to 2.0, the single-scattering albedo increased from 0.87 to 0.99 , and the asymmetry factor decreased from 0.75 to 0.50 . (3) The large variability in the physical and optical properties of aerosols in the FA were attributed to transport events, during which the transported aerosols consisted of varying amounts of dust and smoke particles depending on where they originated (China, Mongolia, or Russia). The results of the numerical sensitivity experiments using the aerosol vertical profiles of the springtime mean and five transport events in the FA are as follows: (1) numerical sensitivity experiments based on simulations conducted with and without aerosols showed that aerosols
\end{abstract}

caused the net downward radiation and the sensible and latent heat fluxes at the surface to decrease. The decrease in temperature in the ABL $(-0.2$ to $-0.6 \mathrm{~K})$ and the direct heating of aerosols in the FA ( 0.0 to $0.4 \mathrm{~K}$ ) strengthened the capping inversion around the top of the ABL. Consequently, the ABL height was decreased by 133 to $208 \mathrm{~m}$ in simulations with aerosols compared to simulations without aerosols. (2) We also conducted simulations in which all aerosols were compressed into the ABL but in which the columnar properties were the same and compared with the simulation results for uncompressed aerosol profiles. The results showed that the reductions in net downward radiation and in sensible and latent heat fluxes were the same in both types of simulations. However, the capping inversion in the simulations with compression was weakened owing to aerosol direct heating in the $\mathrm{ABL}$ and the lack of direct heating in the FA. This resulted in an increase in the ABL height, compared with that in the simulations without compression. (3) The dependencies of the $2 \mathrm{~m}$ temperature and ABL height on the optical thickness and Ångström exponent in the FA were investigated using the results of the numerical sensitivity tests. The $2 \mathrm{~m}$ temperature and $\mathrm{ABL}$ height was decreased with an increase in the optical thickness, and their reduction rates increase with a decrease in the Ångström exponent because the optical thickness in the near-infrared wavelength region was large when the Ångström exponent was small. However, there was a case in which the Ångström exponent was large but the decrease in the ABL height was the largest of all the simulation results. In this case, the strong capping inversion due to the large extinction coefficient around the top of the ABL was an import factor. These results suggest that the vertical profiles of the 
aerosol physical and optical properties, and the resulting direct heating has important effects on the ABL evolution.

\section{Introduction}

Solar radiation heats the Earth's surface, thereby causing thermal instability and evaporation. The thermal energy and water vapor are transported into the atmosphere through turbulent mixing in the atmospheric boundary layer (ABL). These processes in the ABL have important implications for global energy and water circulation. Aerosols have significant impacts on the radiation budget of the Earth because they scatter and absorb solar radiation (aerosol-radiation interaction) and modify cloud physical properties (aerosolcloud interaction) (IPCC, 2013). In this study, we focus on aerosol-radiation interaction and do not consider clouds and precipitation processes. Direct scattering and absorption of solar radiation by aerosols decrease the amount of solar radiation that reaches the Earth's surface, and sensible and latent heat fluxes heat the atmosphere and modify atmospheric stability. These effects have significant impacts on the evolution of the ABL, but the impacts differ depending on the aerosol optical properties (Yu et al., 2002; Pandithurai et al., 2008).

$\mathrm{Yu}$ et al. (2002) and Pandithurai et al. (2008) investigated the influences of aerosol optical properties on the ABL structure using sensitivity experiments with a highresolution ABL model coupled with an accurate radiative transfer model. They showed that the light absorption characteristics of aerosols determine their impact on ABL evolution. However, these studies focused on aerosols only in the ABL. Tsunematsu et al. (2006) examined sounding data obtained by frequently launched sondes and showed that direct heating of transported dust in the free atmosphere (FA) strengthened the capping inversion at the top of the ABL. Therefore, it is also necessary to study the influences of aerosols in the FA on ABL evolution, especially because aerosols in the FA can be transported both regionally and globally (Uno et al., 2009).

Ground-based remote sensing has the advantage that it can be used for continuous monitoring of aerosol vertical profiles. We developed a synergistic method, SKYLIDAR, that retrieves vertical profiles of aerosol optical properties from lidar and sun/sky photometer data (Kudo et al., 2016). SKYLIDAR provides vertical profiles of the extinction coefficient, single-scattering albedo, and phase function, and with these products the solar heating rate can be evaluated (Kudo et al., 2016). Then, by inputting the retrieved aerosol optical properties into an ABL model, it is possible to investigate the influences of aerosols in the ABL and FA on the evolution of the ABL.

This study comprises two parts (Fig. 1). We first evaluated the vertical profiles of aerosol physical and optical properties in a 2-year lidar and sun/sky photometer data set collected at

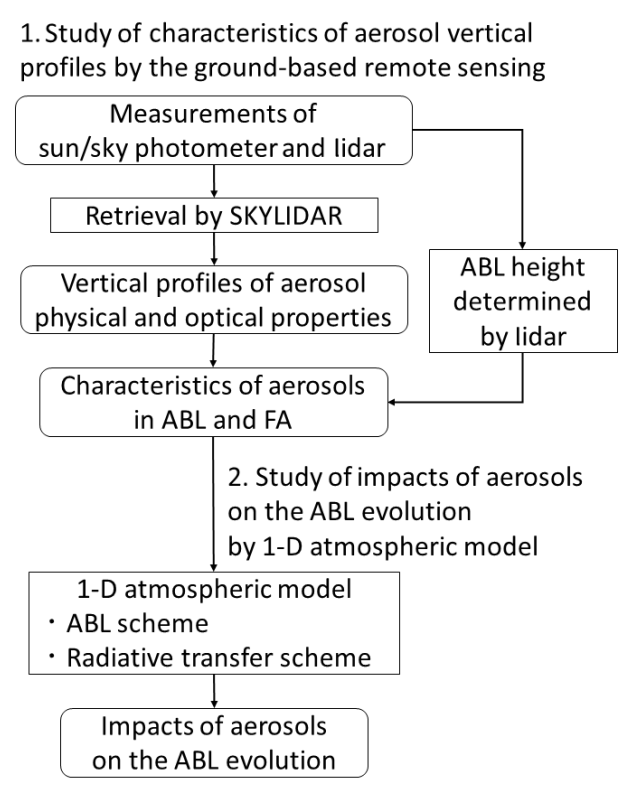

Figure 1. Flow chart of this study.

Tsukuba, Japan, in a rural area located near the megacity of Tokyo. The ABL height was determined from the lidar data to distinguish the locally emitted aerosols in the ABL and the transported aerosols in the FA, and the characteristics of the physical and optical properties in ABL and FA were investigated. The columnar properties of aerosols at Tsukuba have been investigated by many researchers (e.g., Nishizawa et al., 2004; Kudo et al., 2010a, b, 2011), but these previous studies did not investigate their vertical profiles statistically. Second, we investigated the impact of aerosol vertical profiles on the evolution of the ABL by conducting numerical sensitivity experiments with our developed one-dimensional (1-D) atmospheric model, which consists of the ABL and radiative transfer schemes. Details of the data set and methodologies are described in Sect. 2. The characteristics of the aerosol vertical profiles and results of the sensitivity experiments conducted with the 1-D atmospheric model are presented in Sect. 3. Our findings are summarized in Sect. 4.

\section{Data and methodology}

\subsection{Remote sensing of aerosol vertical profiles}

\subsubsection{Data retrieval}

The vertical profiles of aerosol optical and physical properties were estimated from sky radiometer and lidar data obtained by the SKYLIDAR remote sensing method (Kudo et al., 2016). The sky radiometer (Prede Co., Ltd, Tokyo, Japan), deployed in SKYNET (Takamura and Nakajima, 2004), is a scanning photometer that measures direct solar radiation and the angular distribution of diffuse radiation. In 
this study, we used observation data at the Meteorological Research Institute (MRI) of Japan Meteorological Agency (JMA) in Tsukuba $\left(36.05^{\circ} \mathrm{N}, 140.12^{\circ} \mathrm{E}\right.$, about 25 ma.s.1.). Note that our data from the sky radiometer at Tsukuba is not transferred to the International SKYNET Data Center (http://www.skynet-isdc.org/index.php, last access: 28 May 2018). The wavelengths of the sky radiometer data used in this study are $340,380,400,500,675,870$ and $1020 \mathrm{~nm}$. We also used data from a two-wavelength Mie scattering lidar deployed by AD-Net (Sugimoto et al., 2015) at the National Institute for Environmental Studies (NIES) near MRI. The lidar data consisted of the attenuated backscatter coefficients for particle and molecular scattering at 532 and $1064 \mathrm{~nm}$, and the volume depolarization ratio including the contributions of particle and molecular depolarization at $532 \mathrm{~nm}$. The sky radiometer and lidar observation data were collected during 2012 and 2013. As auxiliary data, we used vertical profiles of pressure and temperature from the US National Centers for Environmental Prediction (NCEP) $6 \mathrm{~h}$ reanalysis data set (Kalnay et al., 1996), total ozone from observations made at the JMA Aerological Observatory (AO) near MRI, and surface albedo from the 5-year climatology of the Filled Land Surface Albedo Product, which was generated from the official Terra MODIS-derived Land Surface Albedo Product (Moody et al., 2005, 2007; Moody, 2008). These auxiliary data were used for the calculation of Rayleigh scattering and gas absorption in the SKYLIDAR retrieval. The MRI, NIES and $\mathrm{AO}$ instruments are all located within a circle with a radius of $1 \mathrm{~km}$.

SKYLIDAR estimates aerosol vertical profiles by the following two steps, based on a maximum a posteriori scheme (Kudo et al., 2016). In the first step, the columnar values of the aerosol physical and optical properties (optical thickness, single-scattering albedo, etc.) are estimated by optimizing real and imaginary parts of the refractive index, volume size distribution, and volume ratio of nonspherical particles in the coarse mode to all of the sky radiometer data and the vertical mean of the depolarization ratio of the lidar data. The volume size distribution is assumed to follow a bimodal lognormal distribution, and the volumes, mode radii, and widths of the fine and coarse modes are estimated. The optical properties of nonspherical particles are calculated from a data table of randomly oriented spheroids (Dubovik et al., 2006). In the second step, the vertical profiles of the volume concentrations of fine and coarse modes, the volume ratio of nonspherical particles in the coarse mode, and the real and imaginary parts of the refractive index are optimized to all of the lidar data and to the optical thickness and single-scattering albedo obtained in the first step. The final outputs are vertical profiles of the extinction coefficient, single-scattering albedo, phase function, the real and imaginary parts of the refractive index, the bimodal volume size distribution, and the volume ratio of nonspherical particles in the coarse mode. The output wavelengths of the optical properties are 532 and $1064 \mathrm{~nm}$. Note that the mode radii and width of the fine and coarse modes in the second step are fixed by the columnar values obtained in the first step. These outputs enable us to use the radiative transfer model to calculate the vertical profile of the solar heating rate (Kudo et al., 2016).

In the work of Kudo et al., 2016, we conducted sensitivity tests on SKYLIDAR using the lidar and sky radiometer data simulated for the cases of the transported dust and pollution aerosols. The pollution aerosol was defined as smallsized and light-absorbing particles. The aerosol optical thickness at $500 \mathrm{~nm}$ in the simulation was from 0.05 to 1.2 . The random errors were added to the simulated data. The errors were $\pm 2 \%$ for the direct solar radiation, $\pm 3 \%$ for the diffuse radiation, $\pm 10 \%$ for the attenuated backscatter coefficient, and $\pm 15 \%$ for the volume depolarization ratio. SKYLIDAR successfully retrieved the columnar values (integrated values or vertical means) of the optical thickness, single-scattering albedo, asymmetry factor, real and imaginary parts of the refractive index, and volume size distribution in all the tests. However, the retrieval errors of the vertical profiles increased with a decrease in aerosol optical thickness. For the case in which the aerosol optical thickness at $532 \mathrm{~nm}$ was 0.05 , the retrieval errors were $\pm 0.003 \mathrm{~km}^{-1}$ for the extinction coefficient at $532 \mathrm{~nm}$, and \pm 0.05 for the single-scattering albedo and asymmetry factor at $532 \mathrm{~nm}$. The vertical profiles of the retrieved parameters other than the extinction coefficient had large oscillations due to the random errors of the lidar. In the sensitivity tests for the optical thickness more than 0.1 , the vertical profiles of the size distribution, imaginary part of the refractive index, extinction coefficient, single-scattering albedo, and asymmetry factor of the transported dust were successfully retrieved, but that of the real part of the refractive index was not. In the transported pollution aerosol case, the vertical profiles of the size distribution, real part of the refractive index, extinction coefficient, and asymmetry factor were estimated well, but those of the imaginary parts of the refractive index and single-scattering albedo were not. When SKYLIDAR failed to retrieve the vertical profiles of above-mentioned parameters, the estimated vertical profiles were uniform, and the values were their vertical means.

\subsubsection{Determination of $\mathrm{ABL}$ height}

Locally emitted aerosols in the ABL and the transported aerosols in the FA can have different optical properties, which can be evaluated separately after the ABL height has been determined. We estimated the ABL height from the lidar data by the method of Baars et al. (2008), which is based on the wavelet covariance transform (WCT) with the Haar function. The WCT method is less affected by signal noise than the gradient and variance methods. The local maximum of the WCT vertical profile corresponds to the ABL height, and the local minimum corresponds to the base height of clouds or of transported aerosols. In this study, the ABL height was determined by the following procedure: 
1. The attenuated backscatter coefficients at 532 and $1064 \mathrm{~nm}$ were normalized by their maximum values below $1000 \mathrm{~m}$, and the WCTs for data at 532 and $1064 \mathrm{~nm}$ were calculated.

2. The local minima and maxima of the WCT vertical profiles at 532 and $1064 \mathrm{~nm}$ were detected.

3. The base height of clouds (or transported aerosols) was searched by using a threshold of -0.1 for the local minimum of the WCT at $532 \mathrm{~nm}$.

4. If the base height was not detected in step (3), it was repeated using the WCT at $1064 \mathrm{~nm}$. If the base height was still not detected, it was considered absent or unclear.

5. The ABL height was searched by using a threshold of 0.05 for the local maximum of the WCT at $532 \mathrm{~nm}$ in the daytime, and of the WCT at $1064 \mathrm{~nm}$ at night. The top height of the search range was below the base height, if the base height of clouds or transported aerosols was detected in steps (3) or (4).

6. If the ABL height was not detected, the threshold in step (5) was decreased by -0.01 , and the search was repeated until the threshold reached 0.01 .

7. If the ABL height was not detected in step (6), the search was repeated using the WCT at another wavelength.

8. If the ABL height was not detected in step (7), the ABL height was considered undetermined.

9. The time series of ABL height was smoothed by the running-mean with the time window of $1 \mathrm{~h}$.

Figure 2 shows the examples of the determined ABL height together with the extinction coefficient estimated by SKYLIDAR. The ABL height could be determined very well when transported aerosols were well above the ABL (Fig. 2a). However, when transported aerosols become mixed with the aerosols in the ABL, the ABL height could not be detected (see from 00:00 to 07:00 UTC 2 April in Fig. 2b). In this case, we considered aerosols below base height to be in the ABL and those above to be in the FA. This assumption causes the uncertainties when evaluating the aerosol optical and physical properties in the FA and ABL. However, it is very difficult to evaluate the uncertainties because the mixing of the transported aerosols with those in the ABL makes the ABL height ambiguous, and the ABL height cannot be detected by the lidar data or our eyes. The successful retrievals of the ABL height by the above procedures from (1) to (9) were about $95 \%$ of the 2305 profiles under the clear-sky conditions, and the base height was used as the ABL height in the remaining profiles. Therefore, the influences based on our assumption would be small. (a) 26 February 2013

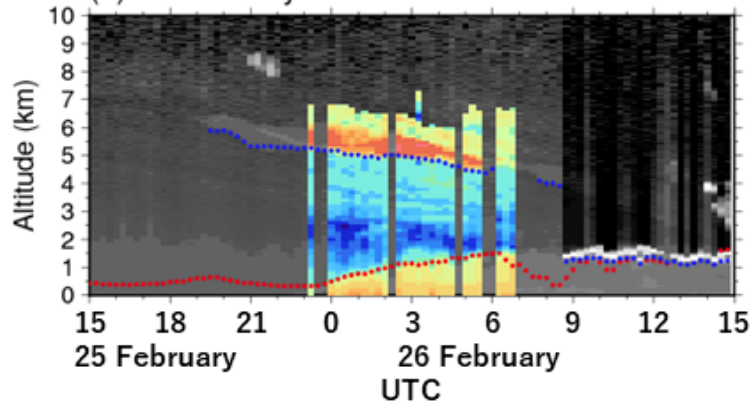

(b) 2 April 2012

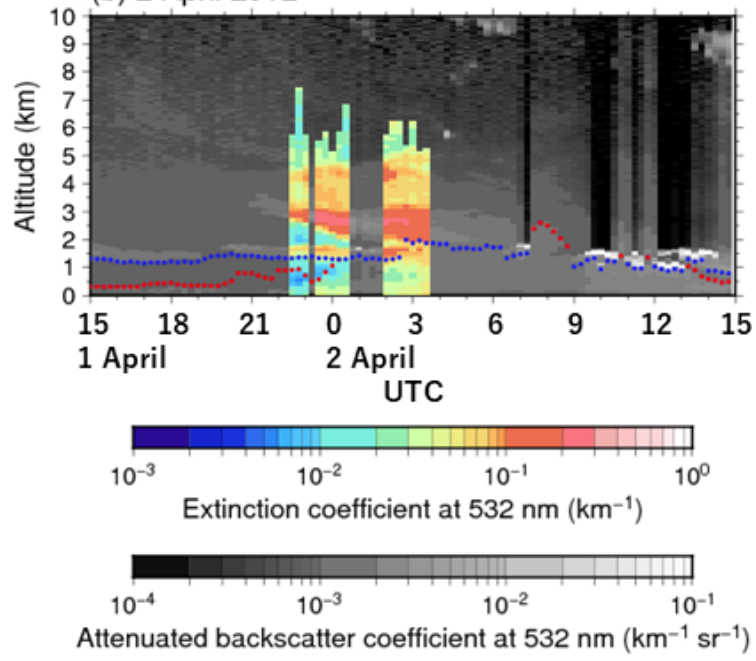

Figure 2. Two examples showing the determined ABL height (red dots) and the base height of clouds or transported aerosols (blue dots).

\subsection{Model simulation}

\subsubsection{1-D atmospheric model}

We developed a 1-D atmospheric model, consisting of ABL and radiative transfer (RT) schemes, and conducted sensitivity experiments to investigate the radiative impact of aerosols on the evolution of the ABL. The ABL scheme in the model is based on the ABL model used as the JMA operational mesoscale model for weather forecasting in Japan. The RT scheme is an RT model developed in our laboratory for the remote sensing of aerosols and clouds, and their impacts on the radiative balance in the solar and infrared wavelength regions (Asano and Shiobara, 1989; Nishizawa et al., 2004; Kudo et al., 2011).

The 1-D atmospheric model has a high-resolution atmospheric vertical grid with 70 layers from the surface to $40 \mathrm{~km}$. The thickness of the bottom layer is $5 \mathrm{~m}$. Turbulent mixing is calculated by the Mellor-Yamada-Nakanishi-Niino level 3 scheme (Nakanishi, 2001; Nakanishi and Niino, 2004, 2006), and calculations of surface fluxes are based on the MoninObukhov similarity using the universal function of Beljaars 
and Holtslag (1991). The vertical grid in the soil has 10 layers from the surface to $2 \mathrm{~m}$ depth, and the soil temperature is calculated by solving the diffusion equation. The water content in the soil layers was fixed in this study.

In the 1-D atmospheric model, vertical diffusion terms for turbulent mixing and vertical advection by a prescribed vertical motion field are considered for the vertical mixing of potential temperature, specific humidity, and the horizontal component of wind. Neither cloud formation nor precipitation is included. In addition, vertical diffusion of aerosols is not considered in the model; aerosol vertical profiles are fixed by the initially given ones.

In the RT scheme, the solar spectrum from $300 \mathrm{~nm}$ to $3.0 \mu \mathrm{m}$ and the infrared spectrum from 4.0 to $50.0 \mu \mathrm{m}$ are divided into 54 and 19 intervals, respectively. The downward and upward fluxes and the heating rate are calculated by the doubling and adding method (Lacis and Hansen, 1974). Gaseous absorption of water vapor, carbon dioxide, oxygen, and ozone are calculated by the correlated k-distribution method. Scattering at the ground surface is assumed to be Lambert reflection.

The aerosol parameters input to the RT scheme are the vertical profiles of the extinction coefficient, single-scattering albedo, and the phase function at wavelengths from $300 \mathrm{~nm}$ to $3.0 \mu \mathrm{m}$. However, the wavelengths of the SKYLIDAR retrievals are limited to 532 and $1064 \mathrm{~nm}$. We determined the refractive index between 532 and $1064 \mathrm{~nm}$ by linear interpolation in a log-log plane and used the refractive index at 532 and $1064 \mathrm{~nm}$ for wavelengths of less than $532 \mathrm{~nm}$ and greater than $1064 \mathrm{~nm}$, respectively (Kudo et al., 2016). The extinction coefficient, single-scattering albedo, and phase function from $300 \mathrm{~nm}$ to $3.0 \mu \mathrm{m}$ were calculated from these refractive index, the volume size distribution, and the volume ratio of the nonspherical particles in the coarse mode. The influences of aerosols on the infrared wavelength region of more than $3.0 \mu \mathrm{m}$ were ignored. The heating ratio estimated by this procedure was now validated now, but the surface solar radiation was compared with the measurements of the pyranometer. The difference was small, about $10 \mathrm{~W} \mathrm{~m}^{-2}$ (Kudo et al., 2016).

\subsubsection{Sensitivity experiments}

We conducted three types of simulation experiments to investigate the impact of aerosols on the evolution of the ABL. The first type was simulations without aerosols (EXP0), the second was simulations using the observed aerosol vertical profile (EXP1), and the third was the same as the second one but with the entire aerosol vertical profile was compressed into the bottom $1 \mathrm{~km}$ (EXP2). Note that the columnar optical properties in EXP1 and EXP2 simulations were the same; only the vertical profile differed between them. Thus, the influences of aerosols can be evaluated from the difference between EXP0 and EXP1 simulations, and the influences of the aerosol vertical profile can be investigated by comparing the results of EXP2 and EXP1 simulations. We conducted experiments using the springtime mean of the aerosol vertical profile and the aerosol vertical profiles observed in the spring during five aerosol transport events in the FA.

To set up the model parameter, we referred to the sensitivity experiments conducted by Yu et al. (2002) and Pandithurai et al. (2008). For our sensitivity experiments, we used the following specified parameters in the 1-D atmospheric model. The integration time of all simulations was $24 \mathrm{~h}$ with a time step of $1 \mathrm{~min}$. The solar orientation was set to that on 5 April 2012 at $36.05^{\circ} \mathrm{N}$. The surface albedo was set to the spring mean of the 5-year climatology of the Filled Land Surface Albedo Product (Moody et al., 2005, 2007; Moody, 2008). The vertical motion was set to the spring mean of the NCEP $6 \mathrm{~h}$ reanalysis data set. The initial vertical profiles of pressure, temperature, specific humidity, and horizontal wind were also set to the spring means of the NCEP $6 \mathrm{~h}$ reanalysis data set. The soil surface was assumed to be bare, and the heat capacity and thermal conductivity in the soil layers were set to $1.3 \times 10^{6} \mathrm{~J} \mathrm{~m}^{-3} \mathrm{~K}^{-1}$ and $0.3 \mathrm{~W} \mathrm{~m}^{-1} \mathrm{~K}^{-1}$, respectively, based on values for dry sandy clay (Kondo, 1994). The initial temperatures in the soil layers were based on the spring mean of the soil temperature observed at the weather observation field of Mito Meteorological Observatory (Ministry of Agriculture, Forestry, and Fisheries, and Japan Meteorological Agency, 1982), which is $60 \mathrm{~km}$ north of the MRI.

Because the sensible and latent heat fluxes at the surface depend on the water content of the soil, we performed sensitivity experiments for both dry and wet soils. The daily means of the sensible and latent heat fluxes in EXP0 for the dry soil case (volumetric water content 0.1 ) were 88 and $78 \mathrm{~W} \mathrm{~m}^{-2}$, respectively. For the wet soil case (volumetric water content 0.2), the sensible heat flux was decreased by $22 \mathrm{~W} \mathrm{~m}^{-2}$, and the latent heat flux was increased by $32 \mathrm{~W} \mathrm{~m}^{-2}$. These differences affected the ABL structures (e.g., temperature and specific humidity) in the EXP1 and EXP2 experiments, but not the impacts of aerosols (i.e., the signs of differences, EXP1 - EXP0 or EXP2 - EXP0 were either both positive or both negative in the dry and wet soil cases, and their absolute values were not significantly different). Therefore, we do not show the results for the wet soil case in this paper. Thus, the volumetric water content in the soil layers was fixed at 0.1 .

\section{Results}

\subsection{Characteristics of aerosol vertical profiles}

\subsubsection{Seasonal characteristics}

Frequency distributions of the extinction coefficient at $532 \mathrm{~nm}$, based on daily means, were obtained for spring (43 analyzed days), summer (7 days), autumn (35 days), and winter (59 days) (Fig. 3). The small number in summer is 


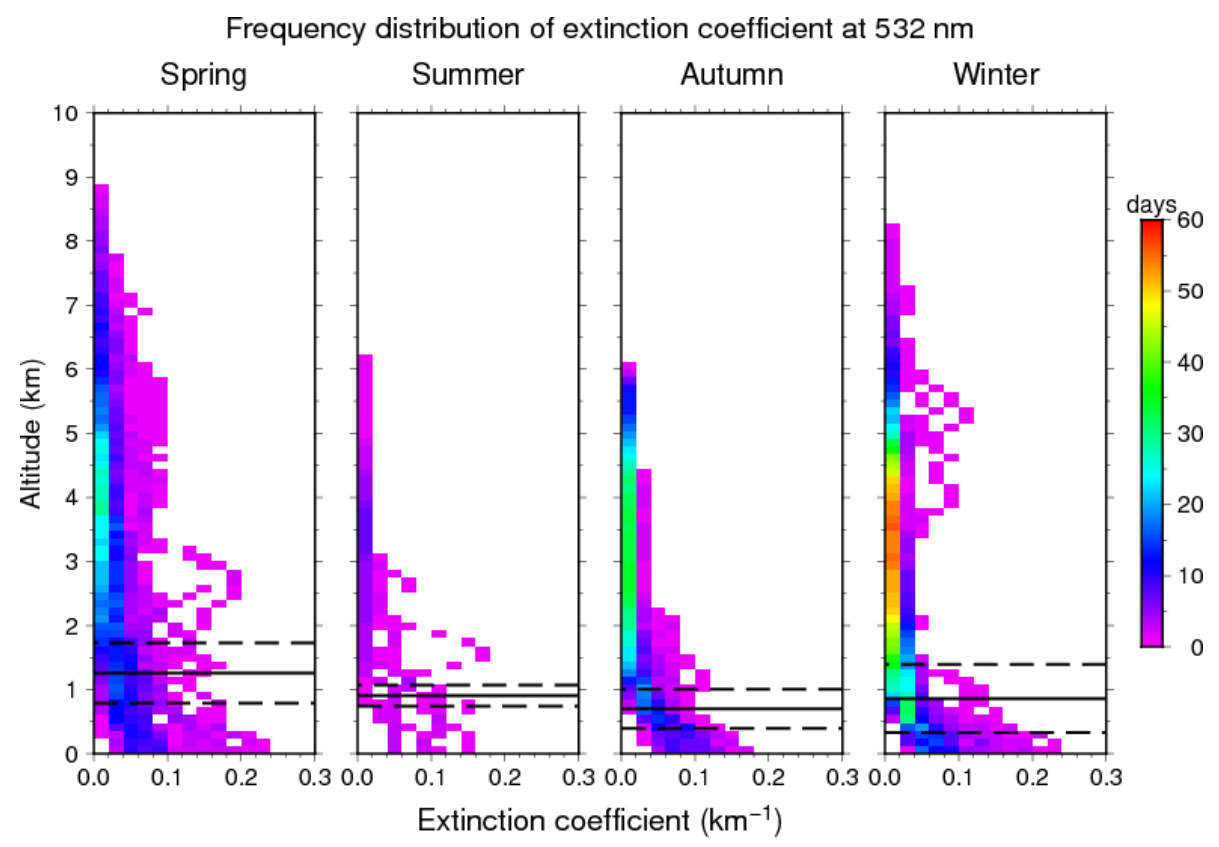

Figure 3. Frequency distributions of the extinction coefficient at $532 \mathrm{~nm}$ by season. The solid horizonal and dashed lines indicate the seasonal means and SDs of the ABL height.

Table 1. Seasonal means and SDs of aerosol optical and physical properties.

\begin{tabular}{|c|c|c|c|c|c|c|c|c|c|}
\hline \multirow{2}{*}{\multicolumn{2}{|c|}{ Physical and optical properties }} & \multicolumn{2}{|c|}{ Spring } & \multicolumn{2}{|c|}{ Summer } & \multicolumn{2}{|c|}{ Autumn } & \multicolumn{2}{|c|}{ Winter } \\
\hline & & $\mathrm{ABL}$ & FA & $\mathrm{ABL}$ & FA & $\mathrm{ABL}$ & FA & $\mathrm{ABL}$ & FA \\
\hline \multicolumn{2}{|l|}{ Optical thickness ${ }^{\mathrm{a}}$} & $0.08 \pm 0.03$ & $0.13 \pm 0.08$ & $0.07 \pm 0.02$ & $0.07 \pm 0.05$ & $0.05 \pm 0.02$ & $0.05 \pm 0.02$ & $0.05 \pm 0.02$ & $0.06 \pm 0.04$ \\
\hline \multicolumn{2}{|l|}{ Ångström exponent } & $0.81 \pm 0.36$ & $0.97 \pm 0.52$ & $0.84 \pm 0.46$ & $1.53 \pm 0.17$ & $1.18 \pm 0.35$ & $1.05 \pm 0.26$ & $1.06 \pm 0.40$ & $1.11 \pm 0.38$ \\
\hline \multicolumn{2}{|c|}{ Single scattering albedo ${ }^{a}$} & $0.93 \pm 0.03$ & $0.96 \pm 0.01$ & $0.92 \pm 0.05$ & $0.92 \pm 0.06$ & $0.96 \pm 0.03$ & $0.95 \pm 0.03$ & $0.96 \pm 0.02$ & $0.96 \pm 0.03$ \\
\hline \multicolumn{2}{|l|}{ Asymmetry factor ${ }^{\mathrm{a}}$} & $0.70 \pm 0.03$ & $0.68 \pm 0.03$ & $0.71 \pm 0.04$ & $0.66 \pm 0.04$ & $0.66 \pm 0.03$ & $0.67 \pm 0.03$ & $0.66 \pm 0.04$ & $0.66 \pm 0.04$ \\
\hline Refractive index ${ }^{a}$ & $\begin{array}{l}\text { real part } \\
\text { imaginary part }\end{array}$ & $\begin{array}{r}1.44 \pm 0.05 \\
0.006 \pm 0.004\end{array}$ & $\begin{array}{r}1.46 \pm 0.04 \\
0.003 \pm 0.002\end{array}$ & $\begin{array}{r}1.41 \pm 0.03 \\
0.006 \pm 0.004\end{array}$ & $\begin{array}{r}1.41 \pm 0.02 \\
0.008 \pm 0.006\end{array}$ & $\begin{array}{r}1.42 \pm 0.04 \\
0.003 \pm 0.002\end{array}$ & $\begin{array}{r}1.41 \pm 0.03 \\
0.003 \pm 0.002\end{array}$ & $\begin{array}{r}1.42 \pm 0.05 \\
0.002 \pm 0.002\end{array}$ & $\begin{array}{r}1.42 \pm 0.03 \\
0.002 \pm 0.002\end{array}$ \\
\hline Mode radius $(\mu \mathrm{m})$ & $\begin{array}{l}\text { fine } \\
\text { coarse }\end{array}$ & \multicolumn{2}{|c|}{$\begin{array}{l}0.14 \pm 0.02 \\
2.83 \pm 1.45\end{array}$} & \multicolumn{2}{|c|}{$\begin{array}{l}0.14 \pm 0.04 \\
4.59 \pm 1.37\end{array}$} & \multicolumn{2}{|c|}{$\begin{array}{l}0.12 \pm 0.03 \\
4.70 \pm 2.00\end{array}$} & \multicolumn{2}{|c|}{$\begin{array}{l}0.11 \pm 0.02 \\
5.89 \pm 2.30\end{array}$} \\
\hline Mode width & $\begin{array}{l}\text { fine } \\
\text { coarse }\end{array}$ & \multicolumn{2}{|c|}{$\begin{array}{l}0.46 \pm 0.13 \\
0.92 \pm 0.10\end{array}$} & \multicolumn{2}{|c|}{$\begin{array}{l}0.59 \pm 0.09 \\
0.98 \pm 0.02\end{array}$} & \multicolumn{2}{|c|}{$\begin{array}{l}0.53 \pm 0.13 \\
0.98 \pm 0.02\end{array}$} & \multicolumn{2}{|c|}{$\begin{array}{l}0.60 \pm 0.13 \\
0.97 \pm 0.06\end{array}$} \\
\hline \multicolumn{2}{|c|}{$\begin{array}{l}\text { Volume ratio of nonspherical } \\
\text { particles in the coarse mode }\end{array}$} & $0.96 \pm 0.06$ & $0.85 \pm 0.22$ & $0.79 \pm 0.20$ & $0.68 \pm 0.21$ & $0.95 \pm 0.08$ & $0.91 \pm 0.09$ & $0.97 \pm 0.07$ & $0.86 \pm 0.14$ \\
\hline \multicolumn{2}{|c|}{ Lidar ratio $^{\mathrm{a}}$} & $69 \pm 10$ & $58 \pm 7$ & $68 \pm 23$ & $65 \pm 13$ & $57 \pm 10$ & $63 \pm 10$ & $56 \pm 9$ & $56 \pm 10$ \\
\hline
\end{tabular}

${ }^{a}$ Wavelength is $532 \mathrm{~nm}$.

due to a lack of completely clear-sky conditions. Summer in Japan is hot and humid, and cumulous clouds develop almost every day. SKYLIDAR can be applied to only the clear-sky condition. In all seasons, the extinction coefficient was large in the layer from the surface to $1.5 \mathrm{~km}$ altitude. This layer is the $\mathrm{ABL}$, and the aerosols in this layer originate primarily from local emissions. In spring and winter, the two large peaks of the extinction coefficients were observed in the layers from 1.5 to $3.5 \mathrm{~km}$ and from 3.5 to $6 \mathrm{~km}$ altitude. These layers are in the FA, and most aerosols in these layers have been transported over long distances. Transported aerosols are frequently observed in the FA in spring, autumn, and winter, when low-pressure systems carrying aerosols emitted in the eastern region of the Eurasian continent frequently pass over Japan. In summer, Japan is dominated by a highpressure system, so it receives fewer transported aerosols. In our data, the optical thickness in summer, autumn, and winter were almost the same in the ABL and FA, but in spring, optical thickness in the FA was 0.13 , larger than 0.08 in the ABL (Table 1).

In general, the ABL is high in summer and low in winter, but in our results, it was higher in winter and spring, and lower in summer and autumn (Fig. 3). The greater ABL heights in winter and spring can be attributed to the mixing of 


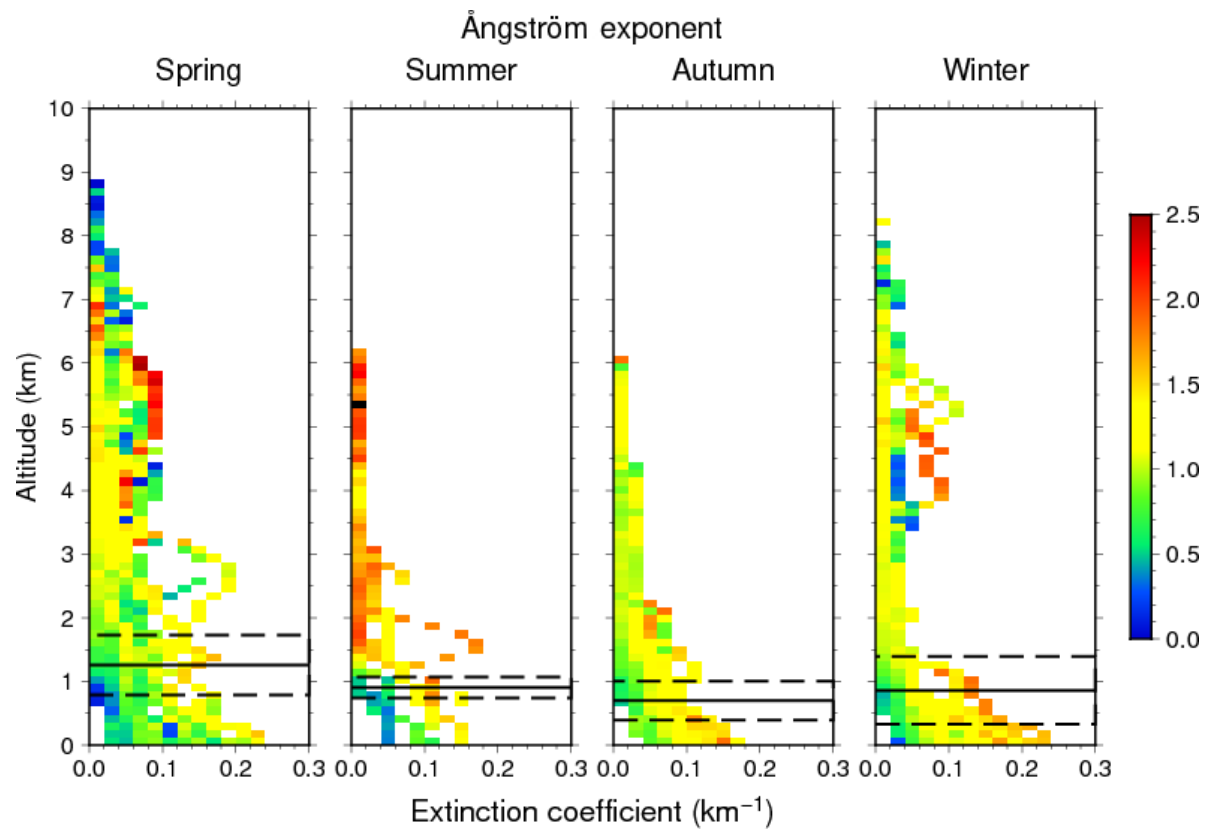

Figure 4. Dependencies of the Ångström exponent on the extinction coefficient at $532 \mathrm{~nm}$ and the altitude by season. The solid and dashed lines indicate the seasonal means and SDs of the ABL height.

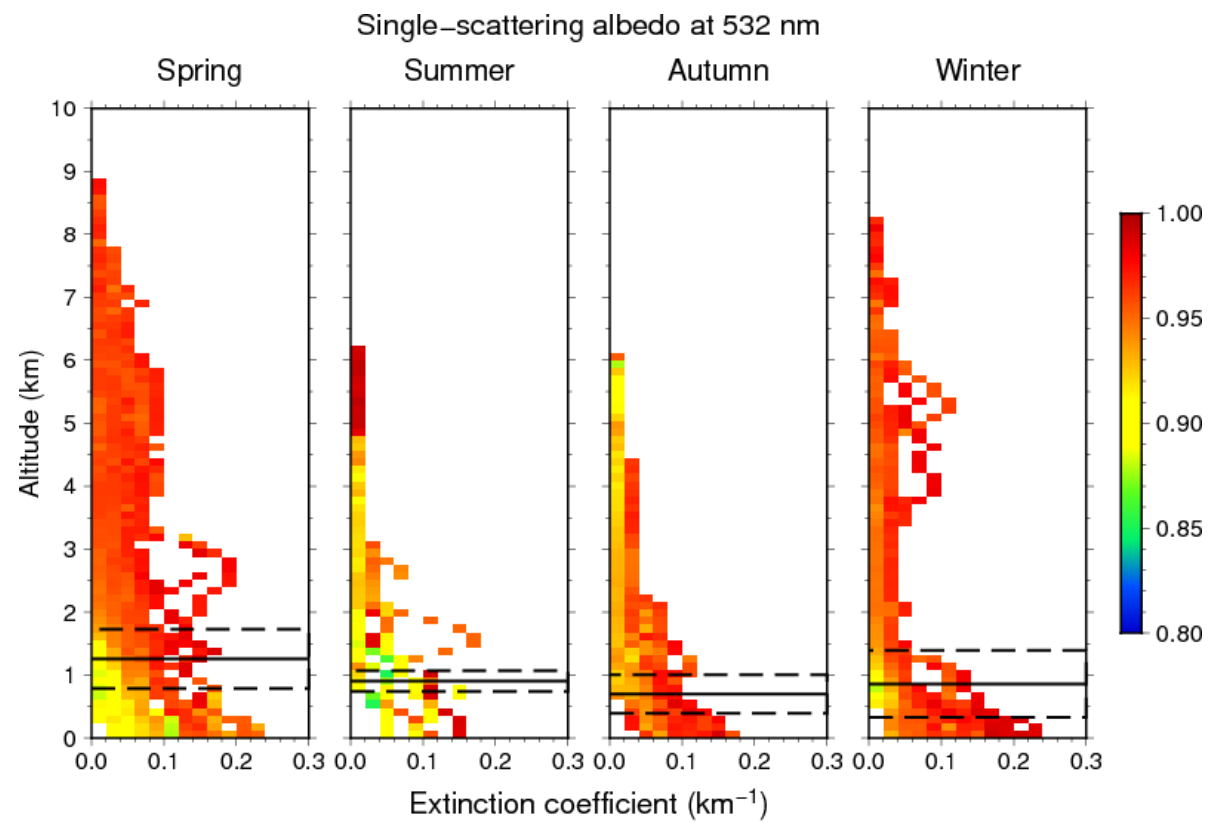

Figure 5. Dependencies of single-scattering albedo on the extinction coefficient at $532 \mathrm{~nm}$ and the altitude by seasons. The solid and dashed lines indicate the seasonal means and SDs of the ABL height.

aerosols between the ABL and FA, which makes it difficult to determine the ABL height (see Sect. 2.1.2). The low ABL height in summer and autumn may be influenced by clouds, which form near the top of the convective mixed layer. Under these circumstances, the ABL height cannot be determined from only lidar data.
The Ångström exponent is a parameter related to particle size: a smaller value indicates a larger particle size. We calculated the vertical profile of the Ångström exponent from the retrievals of the extinction coefficients at 532 and $1064 \mathrm{~nm}$ (Fig. 4). The Ångström exponent in the ABL was from 0.0 to 2.0 in all the seasons and increased as the extinction coefficient increased. This result suggests that large extinction 
coefficients were mainly due to small particles, such as sulfate, nitrate, and organics. Conversely, background aerosols consist of large particles, such as locally emitted mineral dust, likely derived from the large areas of bare soil exposed by agriculture and urban development in Tsukuba. The Ångström exponent in the FA ranged from 0.0 to 2.5. This large variability can be attributed to differences in the composition of aerosols, in particular the proportions of dust and smoke particles during transport events. The characteristics of five transport events are described in Sect. 3.2.

Single-scattering albedo is an important parameter related to light absorption. In the FA, single-scattering albedo was around 0.95 with small variability (Fig. 5 and Table 1), but in the ABL, it was from 0.87 to 0.99 and decreased as the extinction coefficient decreased. In general, the singlescattering albedo of dust particles is small, whereas that of small particles, other than black carbon, is large (Hess et al., 1998; Aoki et al., 2005). The dependency of the singlescattering albedo on the extinction coefficient in the ABL is therefore consistent with the particle size result shown in Fig. 4.

The asymmetry factor is an indicator of how much solar energy reaches the surface: a large asymmetry factor value indicates strong forward scattering, which means that more solar energy reaches the surface. In addition, the value of the asymmetry factor is inversely proportional to that of the Angström exponent. In our results, large variation in the asymmetry factor, from 0.4 to 0.8 , was observed in the FA (Fig. 6). The asymmetry factor in the ABL was from 0.5 to 0.75 , and a dependency of the asymmetry factor on the extinction coefficient was observed.

In Sect. 2.1.1, we described the vertical profiles of the single-scattering albedo and asymmetry factor in the case of the small aerosol optical thickness as being less than 0.1 and containing large retrieval errors due to the signal noises of the lidar data. We should note that the single-scattering albedo and asymmetry factor, where the extinction coefficient was less than $0.02 \mathrm{~km}^{-1}$ in Figs. 5 and 6, might be contaminated with the retrieval errors.

The values of other important optical and physical parameters are shown in Table 1 . These values are particularly useful for comparisons of aerosols in different areas. The values of the real and imaginary parts of the refractive index were from 1.41 to 1.45 and from 0.002 to 0.008 , and they were similar values in both the ABL and FA and in all the seasons. When SKYLIDAR fails to retrieve the vertical profiles of the real part of the refractive index in the transported dust case and the imaginary parts of the refractive index in the transported pollution case, the estimated vertical profiles are uniform and the values are their vertical means (Sect. 2.1). This may cause the similar values of the refractive index in the ABL and FA. The values of the mode radius were from 0.11 to 0.14 for the fine mode and from 2.83 to 5.89 for the coarse mode. They mostly did not differ among seasons, although the coarsemode radius was smaller in spring. The smaller coarse-mode radius in spring reflects the relatively small coarse-mode radius of the transported aerosols, which ranged from 1.93 to $3.61 \mu \mathrm{m}$ (Table 2). In each season, the volume ratio of nonspherical particles in the coarse mode in the ABL was larger than that in the FA, owing to the presence of local dust in the $\mathrm{ABL}$; the smallest value in the ABL was observed in summer, when the ground surface is generally covered with grasses and few dust particles are emitted from the surface. The lidar ratio (extinction to backscatter ratio) is an important parameter for estimating the extinction coefficient, particularly when only the lidar data are available for that purpose. We can calculate the lidar ratio from the single-scattering albedo and phase function in the SKYLIDAR retrievals. In our results, no clear seasonal difference was observed in the lidar ratio, and their values were around 60 .

\subsection{Aerosol transport events in the FA}

The optical thickness in the FA was largest in spring among all seasons because of the presence of transported aerosols. From our results obtained over 2 years, we selected five events for further examination, which occurred on 2 April 2012 and 16 April and 8, 9, and 14 May 2013, characterized by large optical thickness in the FA. The daily means of the optical and physical properties of transported aerosols in the FA on these five dates are summarized in Fig. 7 and Table 2. Large extinction coefficients were observed in the FA during these five transport events (Fig. 7a). In addition, we inferred that the aerosols during the events on 2 April 2012, 16 April, and 14 May 2013 consisted primarily of transported dust, because on these dates the volume of coarse-mode particles was particularly large (Fig. 7b), Ångström exponent values were small, less than 1.0, and the volume ratio of nonspherical particles was large, from 0.84 to 0.99 (Table 2). The 2-day backward trajectories for those events (Fig. 7c and d) suggest that the transported dust originated in desert areas of China and Mongolia. On 8 May 2013, the volume of fine-mode particles was very large (Fig. 7b), the Ångström exponent was also large, 1.82, and the volume ratio of nonspherical particles was the smallest in all the cases (Table 2); these results indicate that the aerosols consisted dominantly of small and spherical particles. The backward trajectory (Fig. 7c and d) indicated that the source region was in Russia, to the southeast area of Lake Baikal, where a forest fire had been observed in early May 2013. Therefore, we interpreted this transported aerosol to consist of transported smoke particles were from that forest fire. The following day, 9 May 2013, the source had moved to northeastern China (Fig. 7c and d), and the volume of coarse-mode particles was large (Fig. 7b); these results suggest that this aerosol may have consisted of transported smoke and dust particles.

The single-scattering albedo and asymmetry factor at $532 \mathrm{~nm}$ of the dust cases (2 April 2012, 16 April, and 14 May 2013), and the smoke and dust mixture case (9 May 2013) were from 0.95 to 0.98 and from 0.65 to 0.71 , re- 


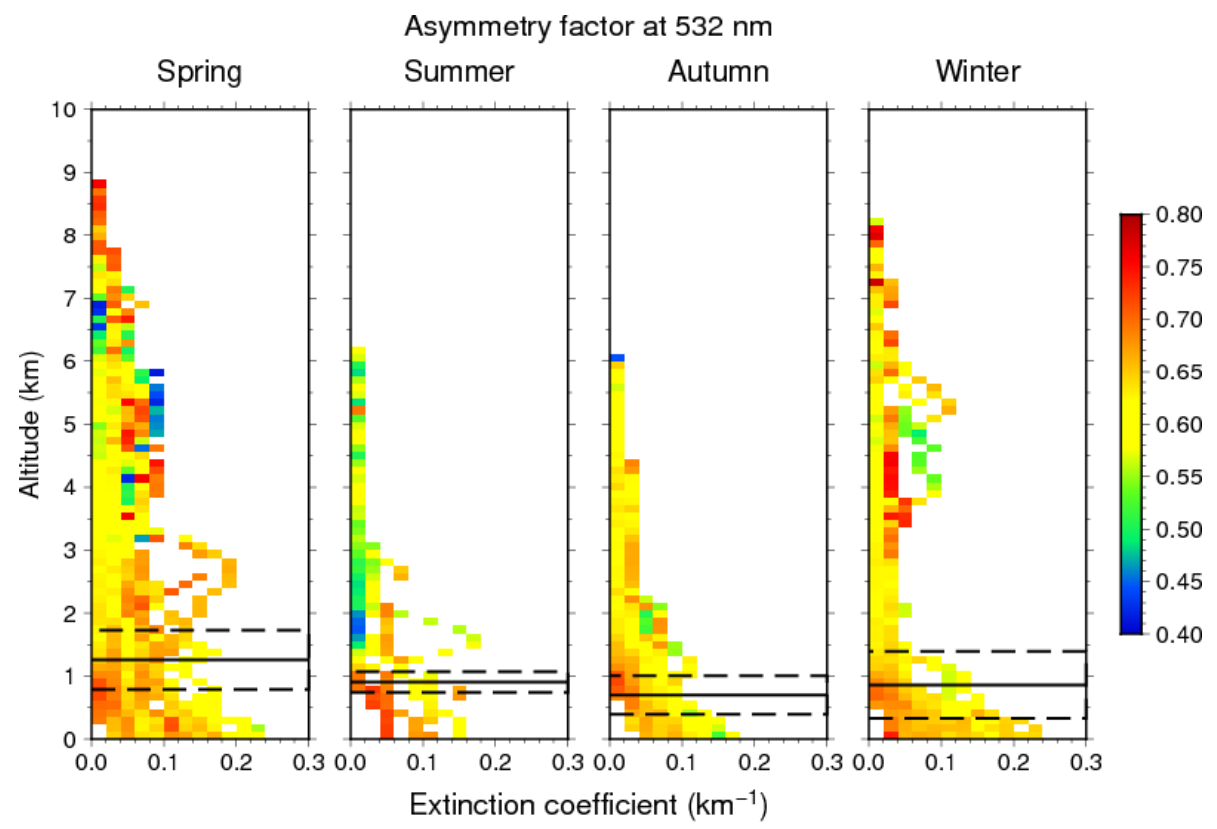

Figure 6. Dependencies of asymmetry factor on the extinction coefficient at $532 \mathrm{~nm}$ and the altitude by season. The solid and dashed lines indicate the seasonal means and SDs of the ABL height.

Table 2. Daily means of optical and physical properties of transported aerosols in the FA.

\begin{tabular}{|c|c|c|c|c|c|}
\hline Physical and optical properties & 2 Apr 2012 & 16 Apr 2013 & 8 May 2013 & 9 May 2013 & 14 May 2013 \\
\hline Optical thickness at $532 \mathrm{~nm}$ & 0.33 & 0.24 & 0.27 & 0.33 & 0.25 \\
\hline Ångström exponent & 0.49 & 0.47 & 1.82 & 1.28 & 0.78 \\
\hline Single-scattering albedo at $532 \mathrm{~nm}$ & 0.98 & 0.97 & 0.97 & 0.96 & 0.95 \\
\hline Asymmetry factor at $532 \mathrm{~nm}$ & 0.68 & 0.71 & 0.64 & 0.65 & 0.68 \\
\hline Real part of the refractive index at $532 \mathrm{~nm}$ & 1.53 & 1.43 & 1.42 & 1.53 & 1.48 \\
\hline $\begin{array}{l}\text { Imaginary part of the refractive index at } \\
532 \mathrm{~nm}\end{array}$ & 0.001 & 0.001 & 0.003 & 0.004 & 0.004 \\
\hline \multirow[t]{2}{*}{ Mode radius $(\mu \mathrm{m}) \quad$ fine } & 0.15 & 0.13 & 0.14 & 0.15 & 0.15 \\
\hline & 2.43 & 2.28 & 2.15 & 3.61 & 1.93 \\
\hline \multirow[t]{2}{*}{ Mode width } & 0.31 & 0.46 & 0.43 & 0.44 & 0.48 \\
\hline & 0.90 & 0.89 & 0.98 & 0.98 & 0.77 \\
\hline $\begin{array}{l}\text { Volume ratio of nonspherical particles in the } \\
\text { coarse mode }\end{array}$ & 0.99 & 0.97 & 0.34 & 0.96 & 0.84 \\
\hline Lidar ratio at $532 \mathrm{~nm}$ & 47 & 56 & 61 & 55 & 56 \\
\hline
\end{tabular}

spectively (Table 2). Dubovik et al. (2002) summarized the global AERONET retrievals and showed the singlescattering albedo and asymmetry factor at visible wavelengths of 0.44 and $0.69 \mu \mathrm{m}$ in the desert regions were from 0.92 to 0.98 and from 0.66 to 0.73 , respectively. Moreover, the single-scattering albedo estimated from the sky radiometer for the Asian dust was from 0.91 to 0.97 (Uchiyama et al., 2005). These retrievals were the columnar values, but the cases that the coarse mode was dominant were selected. Our results were consistent with these results. The refractive index in this study was from 1.43 to 1.53 for the real part and from 0.001 to 0.004 for the imaginary part. Aoki et al. (2005) summarized the refractive index of the dust from the reports of the various works, and showed that the real and imaginary parts at $500 \mathrm{~nm}$ are from 1.45 to 1.55 , and from 0.0005 to 0.008 , respectively. The mode radius for the coarse particles in this study was from 1.93 to $3.61 \mu \mathrm{m}$, and the AERONET retrievals in the desert regions were from 1.9 to $2.7 \mu \mathrm{m}$ (Dubovik et al., 2002). The lidar ratio at $532 \mathrm{~nm}$ in this study was from 47 to 56 , and the results of high spectral resolution lidar or Raman lidar were from 20 to 70 (Burton et al., 2012; Groß et al., 2015). Consequently, the retrieved physical and optical properties of the transported dust were consistent with those reported in other studies. 
(a) Vertical profile

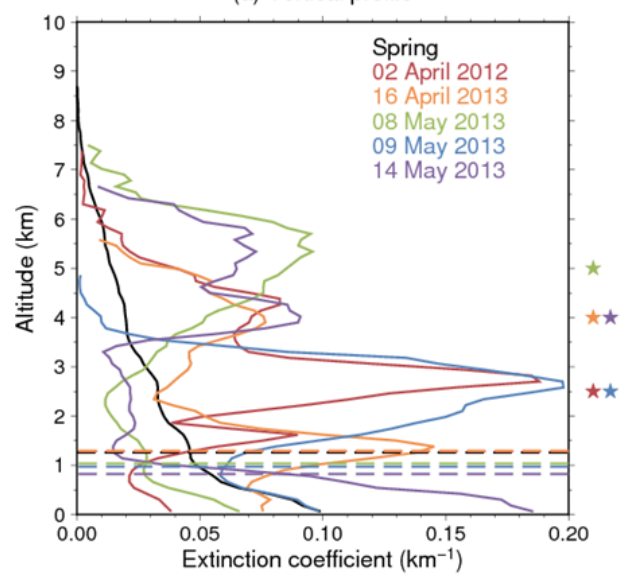

(b) Normalized size distribution in free troposphere

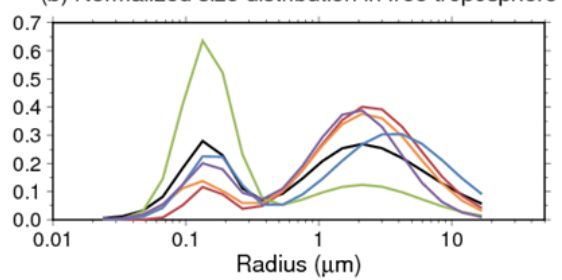

(c) Backward trajectory

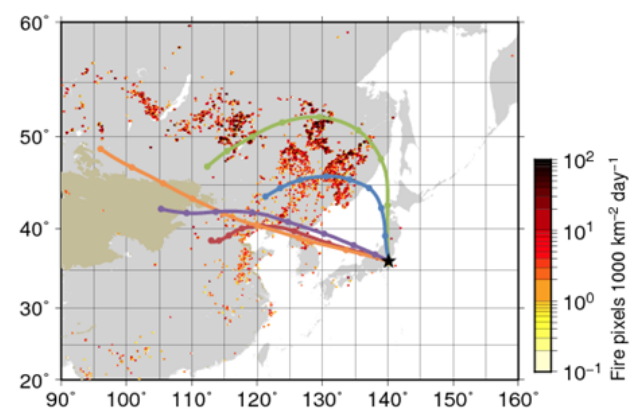

(d) Altitude vs time

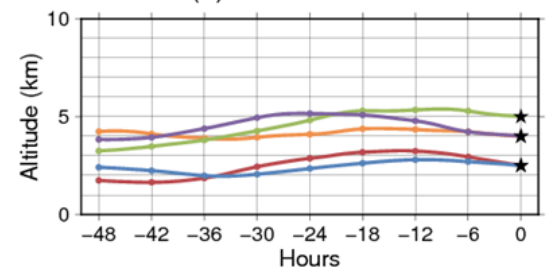

Figure 7. Optical and physical properties of transported aerosols in the FA: (a) vertical profile of the extinction coefficient at $532 \mathrm{~nm}$ with the ABL height (dashed lines), (b) normalized size distribution over the FA, (c) 2-day backward trajectory, and (d) altitude vs. time cross section of the backward trajectory. The stars in (a) indicate the start altitude of the backward trajectories shown in (c). The color scale in (c) indicates fire activity from 1 to 9 May 2013, based on MODIS active-fire product data (NEO, 2016). The ochre color indicates desert regions, based on data from the Land Cover Type Climate Modeling Grid product (LP DAAC, 2013).

For the transported smoke on 9 May 2013, the singlescattering albedo and asymmetry factor were 0.97 and 0.64 , respectively. SKYLIDAR fails to retrieve the vertical profile of the single-scattering albedo of the transported pollution aerosol (small-sized and light-absorbing particle). However, the estimated vertical profile is uniform, and the estimated value is the vertical mean (Sect. 2.1.1). Therefore, our estimated single-scattering albedo can be compared with that of the AERONET retrievals. Furthermore, since the extinction coefficient in the ABL was much smaller than that in the FA (Fig. 7a), the vertical mean of the single-scattering albedo would represent the transported smoke in the FA. The AERONET retrievals at visible wavelengths for the biomassburning aerosols in Amazon forest (Brazil), South American cerrado (Brazil), African savanna (Zambia), and boreal forest (United States and Canada) were from 0.84 to 0.94 for the single-scattering albedo, and from 0.53 to 0.69 for the asymmetry factor (Dubovik et al., 2002). Our estimated asymmetry factor of 0.64 was among these values, but the single scattering albedo of 0.97 was higher than the AERONET retrievals. In general, the smoke from the biomass burning is composed of black carbon, organic carbon, and inorganic materials (Reid et al., 2005). The single-scattering albedo strongly depends on the fuel type and the burning conditions and ranges from 0.2 to 1.0 by depending on the ratio of black carbon (or elemental carbon) to organic carbon in the FLAME-4 experiment (Liu et al., 2013; Pokhrel et al., 2016). The AERONET retrievals for the boreal biomass-burning aerosols in Alaska showed the single-scattering albedo in 2004 and 2005 was about 0.96 (Eck et al., 2009). They suggested a significant amount of smoldering combustion of woody fuels and peat/soil layers that would result in relatively low black carbon mass fractions for smoke particles. The black carbon fraction of the our analyzed transported smoke also might be low. The refractive index of the smoke in this study was 1.42 for the real part and 0.003 for the imaginary part. These values were smaller than those of the AERONET retrievals in the above-mentioned regions, from 1.47 to 1.52 for the real part and from 0.00093 to 0.021 for the imaginary part. Moreover, our results of the refractive index were similar to those of the water-soluble aerosols in the OPAC, which originate from gas-to-particle conversion and consist of various kind of sulfates, nitrates, and other, also organic, water-soluble substances (Hess et al., 1998). This supports the low black carbon fraction and large singlescattering albedo for the smoke in this study. It is possible that the black carbon fraction decreased in the long-range transport from Russia to Japan due to the increase in the water-soluble aerosols. The lidar ratio of 61 at $532 \mathrm{~nm}$ in this study was among the range of the observations by high spec- 
tral resolution lidar or Raman lidar, from 50 to 100 (Burton et al., 2012; Groß et al., 2015).

\subsection{Sensitivity experiment results}

\subsubsection{Impact of aerosols on the evolution of the ABL}

Figure 8 and Table 3 show the results of EXP0 and EXP1 - EXP0. The net downward surface radiation in the solar and infrared wavelength regions, as well as the sensible and latent heat fluxes, were decreased in the EXP1 simulations (with aerosols) compared with EXP0 simulation (without aerosols) (Fig. 7a-c). The change in the daily mean ranged from -14 to $-23 \mathrm{~W} \mathrm{~m}^{-2}$ for the net downward radiation, from -7 to $-11 \mathrm{~W} \mathrm{~m}^{-2}$ for the sensible heat flux, and from -6 to $-10 \mathrm{~W} \mathrm{~m}^{-2}$ for the latent heat flux (Table 3). Absorption by the ground also decreased: the change in the daily value ranged from -1.3 to $-2.2 \mathrm{~W} \mathrm{~m}^{-2}$ (Table 3 ). In general, the downward surface solar radiation becomes small when optical thickness is large, single-scattering albedo is small, and the asymmetry factor is small, (Kudo et al., 2010b). The single-scattering albedo and asymmetry factor were not very different between the springtime mean and the five transport events (Tables 1 and 2), so the reduction in the net downward radiation (Fig. 8a) mainly reflects the optical thickness of the column (Table 3), and the reductions in the sensible and latent heat fluxes were caused by the decrease in the net downward radiation. The potential temperature profile at noon local time decreased in the ABL owing to the decline in the sensible heat flux (Fig. 8d). Note that in the 1-D atmospheric model results, the latent heat flux could not warm the atmosphere in the ABL because condensation is not included in the model. The daily maximum $2 \mathrm{~m}$ temperature was decreased by 0.2 to $0.6 \mathrm{~K}$ (Table 3 ). In contrast, the potential temperature was increased by 0.0 to $0.4 \mathrm{~K}$ in the FA owing to the direct heating of transported aerosols (Fig. 8d). The vertical profiles of direct heating depended on the profiles of the extinction coefficient (Fig. 7a). The warming of the FA and the cooling of the ABL stabilized the atmosphere and strengthened the capping inversion around the top of the $\mathrm{ABL}$. The strengthened capping inversion and the decline of the sensible heat flux caused the ABL height to decrease by -133 to $-208 \mathrm{~m}$ (Fig. 8f and Table 3).

The latent heat flux, that is, the water vapor flux, apparently decreased due to aerosols, but the change in the amount of surface evaporation was small, from -0.21 to $-0.36 \mathrm{~kg} \mathrm{~m}^{-2} \mathrm{day}^{-1}$ (Fig. $8 \mathrm{c}$ and Table 3 ). The change in the vertical profile of specific humidity was very small, but the specific humidity around the top of the ABL was decreased as a result of the decrease in the ABL height and the dry air in the FA (Fig. 8e).

\subsubsection{Impact of the aerosol vertical profile on the evolution of the ABL}

Figure 9 and Table 3 show the results of EXT0 and EXP2 EXP0. Note that the entire aerosol vertical profile was compressed in the bottom $1 \mathrm{~km}$ in the EXP2 simulations, but the optical thickness of the column was the same as that in the EXP1 simulations. The influence of only the aerosol vertical profile can thus be investigated by comparing Figs. 8 and 9 . The reductions in the net downward radiation and the sensible and latent heat fluxes in the EXP2 simulations were almost the same as those in the EXP1 simulations (Fig. 9ac). However, the decrease in the potential temperature in the ABL was about $-0.1 \mathrm{~K}$ at noon and was smaller in EXP2 than in EXP1 (Fig. 9d), because aerosol direct heating in the $\mathrm{ABL}$ was stronger in EXP2 than in EXP1. The changes in surface evaporation (Table 3) and specific humidity (Fig. 9e) in EXP2 were similar to those in EXP1. The aerosol direct heating in the ABL, together with the lack of direct heating in the FA, weakened the capping inversion around the top of the ABL. Therefore, the decrease in the ABL height was from -208 to $-133 \mathrm{~m}$ in EXP1 but those in EXP2 were from -90 to $-24 \mathrm{~m}$ (Table 3). Thus, the evolution of the ABL was changed by the aerosol vertical profile, even though the columnar characteristics of the aerosol optical properties were the same. The impacts of aerosols on the ABL structure, that is, reductions in the temperature in the $\mathrm{ABL}$ and in the ABL height, were larger when aerosols were present in the FA.

\subsubsection{Relations between the aerosol physical and optical properties in the FA and the evolution of the ABL}

The relations between the aerosol physical and optical properties in the FA and the evolution of the ABL were investigated using the EXP1 results for the springtime mean and five transport events. Figure 10 shows the dependencies of the decreases in the daily maximums of the $2 \mathrm{~m}$ temperature and ABL height on the optical thickness and Angström exponent in the FA. We focused on the influences of the Angström exponent to the ABL evolution because the singlescattering albedo and asymmetry factor in the springtime mean and five events had similar values (Table 2). The solid lines in Fig. 10 are the simulation results for different optical thickness and Ångström exponent in the FA with the simplified aerosol vertical profile, where the vertical profiles of the aerosol physical and optical properties are uniform in the $\mathrm{ABL}$ (from the surface to $2 \mathrm{~km}$ altitude) and FA (from 2 to $6 \mathrm{~km}$ altitude), respectively. The physical and optical properties used in the simulations are summarized in Table 4 and are the means calculated from the results of the springtime mean and five transport events. The optical thickness and Ångström exponent in the FA were changed by using the dif- 
(a) Net radiation $\left(\mathrm{W} \mathrm{m}^{-2}\right)$
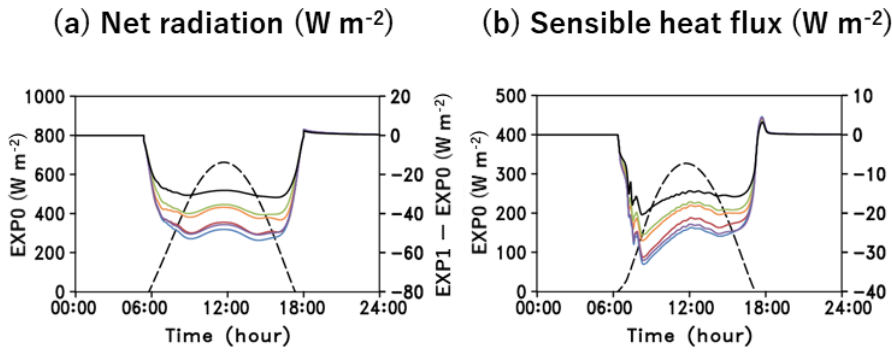

(d) Potential temperature (K)

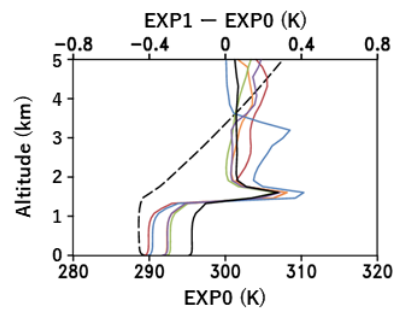

Spring mean 2 April 2012

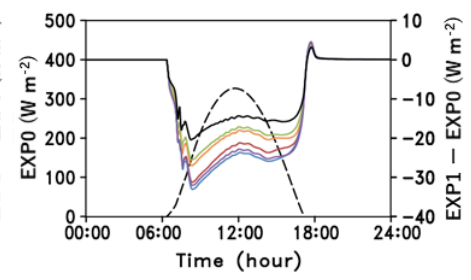

(e) Specific humidity $\left(\mathrm{g} \mathrm{kg}^{-1}\right)$

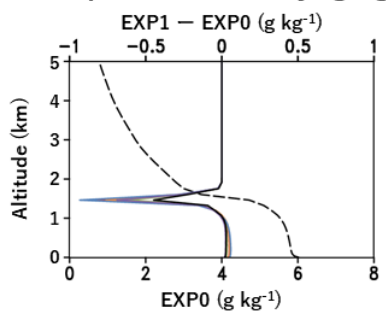

(c) Latent heat flux $\left(\mathrm{W} \mathrm{m}^{-2}\right)$

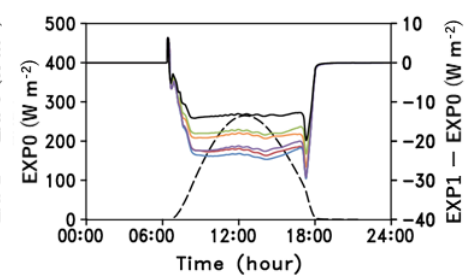

(f) ABL height (m)

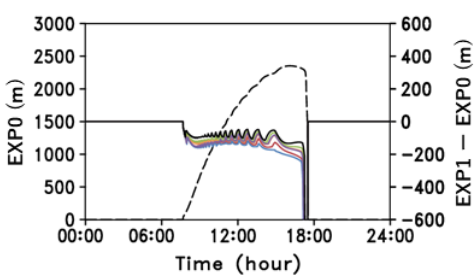

9 May 201314 May 2013

Figure 8. Results of EXP0 (dashed line) and the difference between EXP1 and EXP0 (solid lines): (a) net downward surface radiation, (b) sensible heat flux, (c) latent heat flux, (d) potential temperature at 12:00 LST, (e) specific humidity at 12:00 LST, and (f) ABL height.

Table 3. Results of EXP0, EXP1, and EXP2 sensitivity experiments.

\begin{tabular}{|c|c|c|c|c|c|c|c|c|c|}
\hline & $\begin{array}{l}\text { Aerosol } \\
\text { optical } \\
\text { thickness in } \\
\text { the column } \\
\quad(532 \mathrm{~nm})\end{array}$ & $\begin{array}{l}\text { Daily mean } \\
\text { net } \\
\text { downward } \\
\text { radiation } \\
\quad\left(\mathrm{W} \mathrm{m}^{-2}\right)\end{array}$ & $\begin{array}{l}\text { Daily } \\
\text { mean } \\
\text { sensible } \\
\text { heat flux } \\
\quad\left(\mathrm{W} \mathrm{m}^{-2}\right)\end{array}$ & $\begin{array}{l}\text { Daily } \\
\text { mean } \\
\text { latent } \\
\text { heat flux } \\
\quad\left(\mathrm{W} \mathrm{m}^{-2}\right)\end{array}$ & $\begin{array}{c}\text { Daily } \\
\text { mean } \\
\text { ground } \\
\text { absorption } \\
\quad\left(\mathrm{W} \mathrm{m}^{-2}\right)\end{array}$ & $\begin{array}{c}\text { Daily } \\
\text { mean } \\
\text { of } 2 \mathrm{~m} \\
\text { temperature } \\
(\mathrm{K})\end{array}$ & $\begin{array}{c}\text { Daily } \\
\text { maximum } \\
\text { of } 2 \mathrm{~m} \\
\text { temperature } \\
(\mathrm{K})\end{array}$ & $\begin{array}{c}\text { Daily } \\
\text { integrated } \\
\text { surface } \\
\text { evaporation } \\
\left(\mathrm{kg} \mathrm{m}^{-2} \text { day }^{-1}\right)\end{array}$ & $\begin{array}{l}\text { Daily } \\
\text { maximum } \\
\text { ABL } \\
\text { height } \\
(\mathrm{m})\end{array}$ \\
\hline \multicolumn{10}{|l|}{ EXP0 } \\
\hline Spring mean & 0.0 & 166 & 88 & 78 & -0.6 & 285 & 293 & 2.68 & 2352 \\
\hline EXP1 - EXP0 & & & & & & & & & \\
\hline Spring mean & 0.21 & -14 & -7 & -6 & -1.3 & -0.3 & -0.2 & -0.21 & -133 \\
\hline 2 Apr 2012 & 0.38 & -22 & -10 & -10 & -2.2 & -0.5 & -0.6 & -0.34 & -186 \\
\hline 16 Apr 2013 & 0.35 & -19 & -9 & -8 & -1.8 & -0.4 & -0.4 & -0.29 & -162 \\
\hline 8 May 2013 & 0.32 & -18 & -8 & -8 & -1.7 & -0.4 & -0.4 & -0.27 & -150 \\
\hline 9 May 2013 & 0.42 & -23 & -11 & -10 & -2.2 & -0.5 & -0.5 & -0.36 & -208 \\
\hline 14 May 2013 & 0.37 & -22 & -11 & -10 & -2.1 & -0.5 & -0.5 & -0.33 & -163 \\
\hline \multicolumn{10}{|l|}{ EXP2 - EXP0 } \\
\hline Spring mean & 0.21 & -14 & -7 & -5 & -1.2 & -0.2 & -0.1 & -0.18 & -24 \\
\hline 2 Apr 2012 & 0.38 & -22 & -11 & -9 & -1.9 & -0.4 & -0.2 & -0.30 & -72 \\
\hline 16 Apr 2013 & 0.35 & -19 & -9 & -8 & -1.7 & -0.3 & -0.2 & -0.26 & -83 \\
\hline 8 May 2013 & 0.32 & -18 & -9 & -7 & -1.6 & -0.3 & -0.2 & -0.25 & -77 \\
\hline 9 May 2013 & 0.42 & -23 & -12 & -9 & -2.0 & -0.4 & -0.3 & -0.32 & -90 \\
\hline 14 May 2013 & 0.37 & -22 & -11 & -9 & -1.9 & -0.3 & -0.2 & -0.30 & -70 \\
\hline
\end{tabular}

ferent values of the total volume and volume ratio of the fine and coarse modes for the size distribution.

The $2 \mathrm{~m}$ temperature and the ABL height was decreased with an increase in the optical thickness (Fig. 10). This influence of aerosols was described in Sect. 3.3.1. We found that the reduction rates of the $2 \mathrm{~m}$ temperature and $\mathrm{ABL}$ height increased with a decrease in the Ångström exponent. The small value of the Ångström exponent indicates the large optical thickness in the near-infrared wavelength region. Therefore, large particles such as dust weakened the ABL evolution efficiently due to the influences for both the visible and near-infrared wavelength regions. However, the plots for the springtime mean and five transport events in Fig. 10 were not completely consistent with the solid lines for the simulation results because the aerosol vertical profiles used in the simplified simulations were different from those for the springtime mean and five transport events. Particularly, the decrease in the ABL height on 9 May 2013 (smoke and dust case) was larger than that on 2 April 2012 (dust case). This result is opposite to the above-mentioned influence of the Ångström exponent. In both cases, the optical thickness in the FA was a similar value, about 0.33 . However, the geometric thickness of the aerosol layer in the FA was about $3 \mathrm{~km}$, smaller by $5 \mathrm{~km}$ on 9 May 2013 than on 2 April 2012, and the 
(a) Net radiation $\left(\mathrm{W} \mathrm{m}^{-2}\right)$

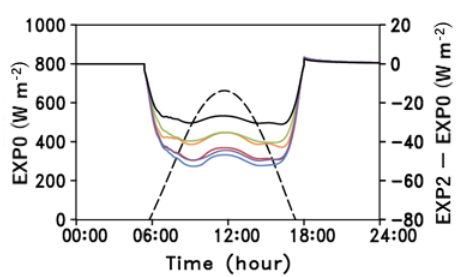

(d) Potential temperature (K)

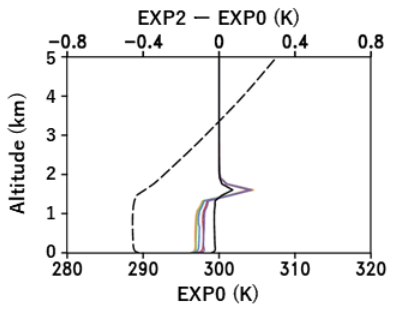

Spring mean 2 April 2012 (b) Sensible heat flux $\left(\mathrm{W} \mathrm{m}^{-2}\right)$

(c) Latent heat flux $\left(\mathrm{W} \mathrm{m}^{-2}\right)$

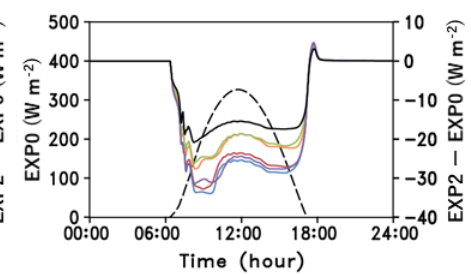

(e) Specific humidity $\left(\mathrm{g} \mathrm{kg}^{-1}\right)$

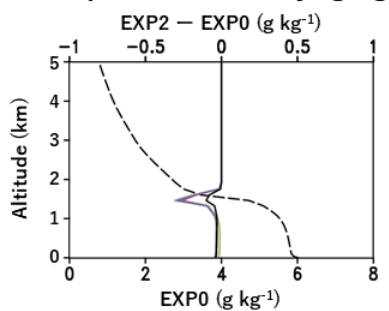

16 April 20138 May 2013

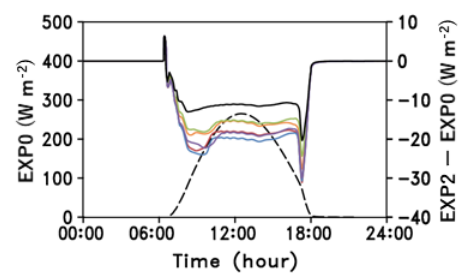

(f) ABL height (m)

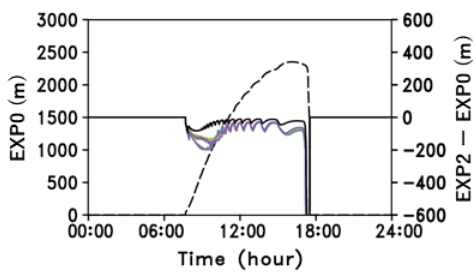

9 May 201314 May 2013

Figure 9. Results of EXP0 (dashed line) and the difference between EXP2 and EXP0 (solid lines): (a) net radiation at the surface, (b) sensible heat flux, (c) latent heat flux, (d) potential temperature at 12:00 LST, (e) specific humidity at 12:00 LST, and (f) ABL height.

(a) Daily maximum of $2 \mathrm{~m}$ temperature $(\mathrm{K})$

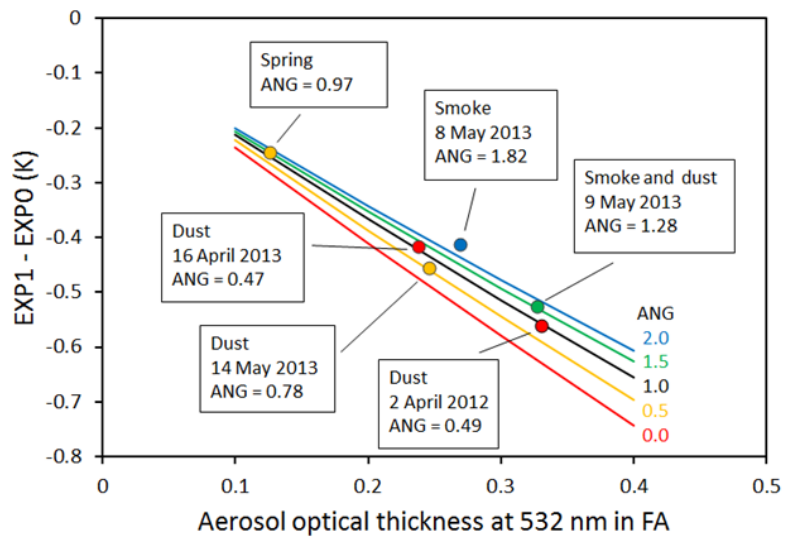

(b) Daily maximum of $A B L$ height (m)

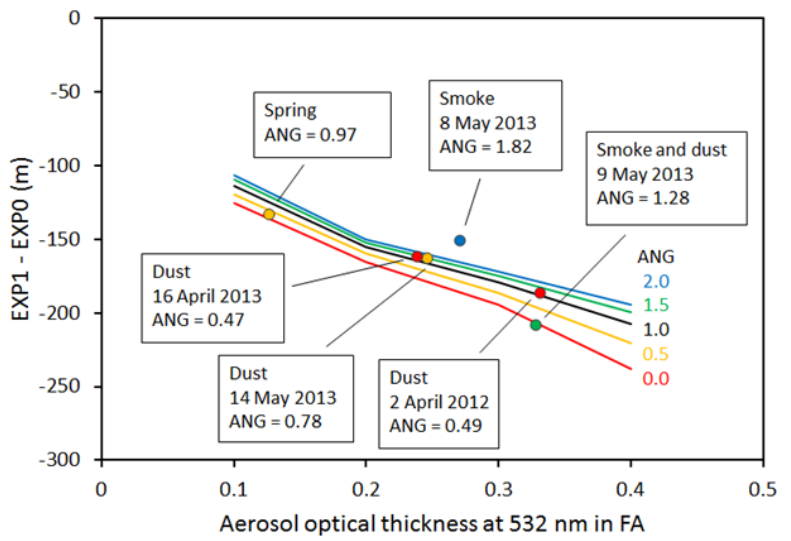

Figure 10. Dependencies of the daily maximum $2 \mathrm{~m}$ temperature (a) and the daily maximum ABL height (b) on the aerosol optical thickness and Ångström exponent in the FA. The ANG indicates Ångström exponent. The color of filled circle indicates the value of the Ångström exponent, from 0.0 to 0.5 (red), from 0.5 to 1.0 (orange), from 1.0 to 1.5 (green), and from 1.5 to 2.0 (blue). The solid lines are the results of the model simulations for the simplified aerosol vertical profile described in the text.

extinction coefficient from 1.0 to $3.5 \mathrm{~km}$ altitude was larger on 9 May 2013 than on 2 April 2012 (Fig. 7a). This resulted in the largest temperature increase in the FA and a strong capping inversion on 9 May 2013 (Fig. 8d). Consequently, the ABL height was low on 9 May 2013. The dependencies of the $2 \mathrm{~m}$ temperature and ABL height on the Angström exponent were found in this study, but the most important factor was the vertical profile of the extinction coefficient, in particular the extinction coefficient around the top of the ABL.

\section{Conclusion}

We first investigated vertical profiles of aerosol physical and optical properties at Tsukuba, Japan, with focus on the seasonal means and on five aerosol transport events, using a synergistic remote sensing method (SKYLIDAR) using sky radiometer and lidar data over 2 years (2012 and 2013). Second, we investigated the impact of the aerosol vertical profile on the evolution of the ABL by conducting sensitivity experiments with our 1-D atmospheric model.

The vertical profiles of the seasonal mean extinction coefficients showed high loads of the locally emitted aerosols in 
Table 4. Physical and optical properties used in the simulations for the simplified aerosol vertical profiles in Fig. 10.

\begin{tabular}{|c|c|c|}
\hline Physical and optical properties & $\mathrm{ABL}$ (surface to $2 \mathrm{~km}$ altitude) & FA ( 2 to $6 \mathrm{~km}$ altitude) \\
\hline Optical thickness at $532 \mathrm{~nm}$ & 0.083 & 0.1 to 0.4 \\
\hline Ångström exponent & 0.86 & 0.0 to 2.0 \\
\hline Real part of the refractive index at all the wavelengths & 1.45 & 1.48 \\
\hline Imaginary part of the refractive index at all the wavelengths & 0.005 & 0.003 \\
\hline \multirow{2}{*}{$\begin{array}{ll}\text { Mode radius }(\mu \mathrm{m}) & \text { fine } \\
& \text { coarse }\end{array}$} & 0.15 & 0.15 \\
\hline & 2.5 & 2.5 \\
\hline \multirow[t]{2}{*}{ Mode width } & 0.40 & 0.40 \\
\hline & 0.90 & 0.90 \\
\hline Volume ratio of nonspherical particles in the coarse mode & 0.97 & 0.82 \\
\hline
\end{tabular}

the ABL, from the surface to $1.5 \mathrm{~km}$ altitude, and the transported aerosols in the FA, from 1.5 to $6 \mathrm{~km}$ altitude. In summer, autumn, and winter, the aerosol optical thickness was almost the same in the ABL and FA. In spring, the optical thickness at $532 \mathrm{~nm}$ in the FA was 0.13 and was larger than 0.08 in the ABL.

The physical and optical properties of the aerosols in the ABL were dependent on the extinction coefficient: as the extinction coefficient increased from 0.02 to $0.24 \mathrm{~km}^{-1}$, the Ångström exponent increased from 0.0 to 2.0 , the singlescattering albedo increased from 0.87 to 0.99 , and the asymmetry factor decreased from 0.75 to 0.5 . These characteristics suggest that the background aerosols consisted of the locally emitted dust particles and the large extinction coefficient was attributed to an increase in the small and nonabsorbing particles.

The optical and physical properties in the FA varied greatly owing to the presence of transported aerosols. We investigated the vertical profiles and backward trajectories of five transport events. In three events, the aerosol consisted of dust particles transported from desert regions of China and Mongolia. In one event, the aerosol consisted of small smoke particles transported from a forest fire in Russia. The aerosols of a fifth event consisted of both small and large particles, which we interpreted as smoke and dust particles, respectively. The single-scattering albedo and asymmetry factor of the transported dust particles and mixture of dust and smoke particles were from 0.95 to 0.98 and from 0.65 to 0.71 . These values were consistent with those reported in the other works for the Asian dust and the desert regions in the world. In the transported smoke case, the asymmetry factor was 0.64 and was consistent with the reports for the biomass-burning aerosols in the world. However, the single-scattering albedo was 0.97 and was higher than the other reports. It is supposed that the black carbon fraction was low in the source of the smoke, or the black carbon fraction decreased in the long-range transport from Russia to Japan.

We conducted sensitivity experiments in which the aerosol vertical profiles of the springtime mean and the five transport events were input to our 1-D atmospheric model. The sensitivity experiments with (EXP1) and without aerosols
(EXP0) showed that the aerosols decreased net downward surface radiation $\left(-14\right.$ to $\left.-23 \mathrm{~W} \mathrm{~m}^{-2}\right)$ and sensible and latent heat fluxes $\left(-7\right.$ to -11 and -6 to $-10 \mathrm{~W} \mathrm{~m}^{-2}$, respectively). These resulted in a decrease in the maximum $2 \mathrm{~m}$ temperature $(-0.2$ to $-0.6 \mathrm{~K})$. The decrease in the temperature in the ABL and the direct heating of the transported aerosols in the FA strengthened the capping inversion near the top of the ABL. Consequently, the ABL height was less developed in the EXP1 simulations than in the EXP0 simulations, and the decrease in the ABL height due to aerosols was from -133 to $-208 \mathrm{~m}$.

To investigate the impact of only the aerosol vertical profile on the evolution of the ABL, we conducted simulations (EXP2) in which all aerosols were compressed into the ABL (0-1 km altitude), but in which the columnar optical thickness was the same as that in the EXP1 simulations. The net downward radiation and the sensible and latent heat fluxes were not changed, but the ABL height was increased, in EXP2 simulations compared with EXP1 simulations. This increase in the ABL height resulted from a weakened capping inversion caused by aerosol direct heating in the ABL and the lack of direct heating in the FA.

Using the results of EXP1 simulations for the springtime mean and five transport events, the dependencies of the decreases in the $2 \mathrm{~m}$ temperature and ABL height on the optical thickness and Ångström exponent in the FA were investigated. The $2 \mathrm{~m}$ temperature and ABL height decreased with an increase in the optical thickness, and their reduction rates depended on the Angström exponent. The $2 \mathrm{~m}$ temperature and ABL height efficiently decreased in the case in which the Angström exponent was small because of the large optical thickness in the near-infrared wavelength region. However, in the case of the smoke and dust mixture event, the Angström exponent was large, but the decrease in the ABL height was largest in the springtime mean and five events. The extinction coefficient around the top of the ABL was largest in the five transport events, and the strong capping inversion resulted in the lowest ABL height.

These sensitivity experiment results suggest that the vertical profiles of the aerosol physical and optical properties, and resulting direct heating are essential factors in the evolution 
of the ABL. Moreover, it is particularly important to characterize aerosol optical properties in the FA because aerosols in the FA can be transported widely and therefore affect the ABL both regionally and globally.

Our 1-D atmospheric model did not consider cloud formation or precipitation, although both of these can be affected by aerosol-induced modification of atmospheric stability. In the future, we plan to develop a 1-D or 3-D model that includes these processes and investigate aerosol-cloud interactions by inputting the observed aerosol data into the models.

Data availability. The lidar data are available from the ADNet (http://www-lidar.nies.go.jp; AD-Net Data Center, 2016). The sky radiometer data are available from the International SKYNET Data Center (http://www.skynet-isdc.org/index. php; SKYNET Data Center, 2018), but the sky radiometer data at Tsukuba, Japan are available on request by contacting the first author of the paper.

Competing interests. The authors declare that they have no conflict of interest.

Special issue statement. This article is part of the special issue "SKYNET - the international network for aerosol, clouds, and solar radiation studies and their applications (AMT/ACP inter-journal SI)". It is not associated with a conference.

Acknowledgements. This work was supported by the Japan Society for the Promotion of Science KAKENHI grant nos. 24510026, $15 \mathrm{H} 01728$, and $15 \mathrm{H} 02808$. NCEP reanalysis data were provided by the NOAA/OAR/ESRL PSD (Boulder, Colorado, USA) website at http://www.esrl.noaa.gov/psd/ (last access: 28 May 2018). The MODIS MCD12C1 product was retrieved from the online data pool, courtesy of the NASA EOSDIS Land Processes Distributed Active Archive Center (LP DAAC), USGS/Earth Resources Observation and Science (EROS) Center, Sioux Falls, South Dakota (https://lpdaac.usgs.gov/data_access/data_pool, last access: July 2015).

Edited by: Stelios Kazadzis

Reviewed by: three anonymous referees

\section{References}

AD-Net Data Center: The lidar data, available at: http://www-lidar. nies.go.jp/, last access: 22 July 2016.

Aoki, T., Tanaka, T. Y., Uchiyama, A., Chiba, M., Mikami, M., Yabuki, S., and Key, J. R.: Sensitivity experiments of direct forcing caused by mineral dust simulated with a chemical transport model, J. Meteorol. Soc. Jpn., 83A, 315-331, 2005.

Asano, S. and Shiobara, M.: Aircraft measurements of the radiative effects of tropospheric aerosols: I. Observational results of the radiation budget, J. Meteorol. Soc. Jpn., 67, 847-861, 1989.
Baars, H., Ansmann, A., Engelmann, R., and Althausen, D.: Continuous monitoring of the boundary-layer top with lidar, Atmos. Chem. Phys., 8, 7281-7296, https://doi.org/10.5194/acp-8-72812008, 2008.

Beljaars, A. C. M. and Holtslag, A. A. M.: Flux parameterization over land surfaces for atmospheric models, J. Appl. Meteorol., 30, 327-341, 1991.

Burton, S. P., Ferrare, R. A., Hostetler, C. A., Hair, J. W., Rogers, R. R., Obland, M. D., Butler, C. F., Cook, A. L., Harper, D. B., and Froyd, K. D.: Aerosol classification using airborne High Spectral Resolution Lidar measurements methodology and examples, Atmos. Meas. Tech., 5, 73-98, https://doi.org/10.5194/amt-5-73-2012, 2012.

Dubovik, O., Holben, B., Eck, T. F., Smirnov, A., Kaufman, Y. J., King, M. D., Tanré, D., and Slutsker, I.: Varaiability of absorption and optical properties of key aerosol types observed in worldwide locations, J. Atmos., Sci., 59, 590-608, 2002.

Dubovik, O., Sinyuk, A., Lapyonok, T., Holben, B. N., Mishchenko, M., Yang, P., Eck, T. F., Volten, H., Muñoz, O., Veihelmann, B., van der Zande, W. J., Leon, J. F., Sorokin, M., and Slutsker, I.: Application of spheroid models to account for aerosol particle nonsphericity in remote sensing of desert dust, J. Geophys. Res.-Atmos., 111, 1-34, https://doi.org/10.1029/2005JD006619, 2006.

Eck, T. E., Holben, B. N., Reid, J. S., Sinyuk, A., Hyer, E. J., O’Neill, N. T., Shaw, G. E., Vande Castle, J. R., Chapin, F. S., Dubovik, O., Smirnov, A., Vermote, E., Schafer, J. S., Giles, D., Slutsker, I., Sorokine, M., and Newcomb, W. W.: Optical properties of boreal region biomass burning aerosols in central Alaska and seasonal variation of aerosol optical depth at an Arctic coastal site, J. Geophys. Res., 114, D11201, https://doi.org/10.1029/2008JD010870, 2009.

Groß, S., Freudenthaler, V., Schepanski, K., Toledano, C., Schäfler, A., Ansmann, A., and Weinzierl, B.: Optical properties of long-range transported Saharan dust over Barbados as measured by dual-wavelength depolarization Raman lidar measurements, Atmos. Chem. Phys., 15, 11067-11080, https://doi.org/10.5194/acp-15-11067-2015, 2015.

Hess, M., Koepke, P., and Schult, I.: Optical properties of aerosols and clouds: the software package OPAC, B. Am. Meteorol. Soc., 79, 831-844, 1998

IPCC: Climate Change 2013: The Physical Science Basis. Contribution of Working Group I to the Fifth Assessment Report of the Intergovernmental Panel on Climate Change, edited by: Stocker, T. F., Qin, D., Plattner, G.-K., Tignor, M., Allen, S. K., Boschung, J., Nauels, A., and Xia, Y., Cambridge University Press, Cambridge, UK and New York, NY, USA, 2013.

Kalnay, E., Kanamitsu, M., Kistler, R., Collins, W., Deaven, D., Gandin, L., Iredell, M., Saha, S., White, G., Woollen, J., Zhu, Y., Chelliah, M., Ebisuzaki, W., Higgins, W., Janowiak, J., Mo, K. C., Ropelewski, C., Wang, J., Leetmaa, A., Reynolds, R., Jenne, R., and Joseph, D.: The NCEP/NCAR 40-year reanalysis project, B. Am. Meteorol. Soc., 77, 437-471, 1996.

Kondo, J.: Mizukankyo-no-kisyougaku, 2nd edn., Asakura Publishing Co. Ltd., Tokyo, 1994 (in Japanese).

Kudo, R., Uchiyama, A., Yamazaki, A., Sakami, T., and Kobayashi, E.: From solar radiation measurements to optical properties: 1998-2008 trends in Japan, Geophys. Res. Lett., 37, 1-6, https://doi.org/10.1029/2009GL041794, 2010a. 
Kudo, R., Uchiyama, A., Yamazaki, A., and Kobayashi, E.: Seasonal characteristics of aerosol radiative effect estimated from ground-based solar radiation measurements in Tsukuba, Japan, J. Geophys. Res.-Atmos., 115, 1-10, https://doi.org/10.1029/2009JD012487, 2010b.

Kudo, R., Uchiyama, A., Yamazaki, A., Sakami, T., and Ijima, O.: Decadal changes in aerosol optical thickness and single scattering albedo estimated from ground-based broadband radiometers: a case study in Japan, J. Geophys. Res.-Atmos., 116, 1-14, https://doi.org/10.1029/2010JD014911, 2011.

Kudo, R., Nishizawa, T., and Aoyagi, T.: Vertical profiles of aerosol optical properties and the solar heating rate estimated by combining sky radiometer and lidar measurements, Atmos. Meas. Tech., 9, 3223-3243, https://doi.org/10.5194/amt-9-3223-2016, 2016.

Lacis, A. A. and Hansen, J. E.: A parameterization for the absorption of solar radiation in the Earth's atmosphere, J. Atmos. Sci., 31, 118-133, 1974.

Liu, S., Aiken, A. C., Arata, C., Dubey, M. K., Stockwell, C. E., Yokelson, R. J., Stone, E. A., Jayarathne, T., Robinson, A. L., DeMott, P. J., and Kreidenweis, S. M.: Aerosol single scattering albedo dependence on biomass combustion efficiency: laboratory and field studies, Geophys. Res. Lett., 41, 742-748, https://doi.org/10.1002/2013GL058392, 2013.

LP DAAC: Land Processes Distributed Active Archive Center: The Land Cover Type Climate Modeling Grid (CMG) product (MCD12C1), Version 051, NASA EOSDIS Land Processes DAAC, USGS Earth Resources Observation and Science (EROS) Center, Sioux Falls, South Dakota, available at: https://lpdaac.usgs.gov/dataset_discovery/modis/modis_ products_table/mcd12c1 (last access: 20 May 2007), 2013.

Ministry of Agriculture, Forestry, and Fisheries, and Japan Meteorological Agency: Chichu-ondo-nado-ni-kansuru-shiryou [Report about the soil temperature], Ministry of Agriculture, Forestry, and Fisheries, Tokyo, 1982 (in Japanese).

Moody, E. G.: MODIS-derived spatially complete surface albedo products: spatial and temporal pixel and zonal averages, J. Appl. Meteorol. Climatol., 47, 2879-2894, https://doi.org/10.1175/2008JAMC1795.1, 2008.

Moody, E. G., King, M. D., Platnick, S., Schaaf, C. B., and Gao, F.: Spatially complete global spectral surface albedos: value-added datasets derived from terra MODIS land products, IEEE T. Geosci. Remote, 43, 144-157, https://doi.org/10.1109/TGRS.2004.838359, 2005.

Moody, E. G., King, M. D., Schaaf, C. B., Hall, D. K., and Platnick, S.: Northern Hemisphere five-year average (2000-2004) spectral albedos of surfaces in the presence of snow: statistics computed from Terra MODIS land products, Remote Sens. Environ., 111, 337-345, https://doi.org/10.1016/j.rse.2007.03.026, 2007.

Nakanishi, M.: Closure model based on large-eddy simulation data, Bound. Lay. Meteorol., 99, 349-378, 2001.

Nakanishi, M. and Niino, H.: An improved Mellor-Yamada Level-3 model with condensation physics: its design and verification, Bound.-Lay. Meteorol., 112, 1-31, https://doi.org/10.1023/B:BOUN.0000020164.04146.98, 2004.
Nakanishi, M. and Niino, H.: An improved Mellor-Yamada Level-3 model: its numerical stability and application to a regional prediction of advection fog, Bound.-Lay. Meteorol., 119, 397-407, https://doi.org/10.1007/s10546-005-9030-8, 2006.

NEO: NASA Earth Observatory: The Imagery of MODIS Active Fire, available at: http://neo.sci.gsfc.nasa.gov/ (last access: 16 July 2016), 2016.

Nishizawa, T., Asano, S., Uchiyama, A., and Yamazaki, A.: Seasonal variation of aerosol direct radiative forcing and optical properties estimated from ground based radiative measurements, J. Atmos. Sci., 61, 57-72, 2004.

Pandithurai, G., Seethala, C., Murthy, B. S., and Devara, P. C. S.: Investigation of atmospheric boundary layer characteristics for different aerosol absorptions: case studies using CAPS model, Atmos. Environ., 42, 4755-4768, https://doi.org/10.1016/j.atmosenv.2008.01.038, 2008.

Pokhrel, R. P., Wagner, N. L., Langridge, J. M., Lack, D. A., Jayarathne, T., Stone, E. A., Stockwell, C. E., Yokelson, R. J., and Murphy, S. M.: Parameterization of single-scattering albedo (SSA) and absorption Ångström exponent (AAE) with EC/OC for aerosol emissions from biomass burning, Atmos. Chem. Phys., 16, 9549-9561, https://doi.org/10.5194/acp-169549-2016, 2016.

Reid, J. S., Koppmann, R., Eck, T. F., and Eleuterio, D. P.: A review of biomass burning emissions part II: intensive physical properties of biomass burning particles, Atmos. Chem. Phys., 5, 799825, https://doi.org/10.5194/acp-5-799-2005, 2005.

SKYNET Data Center: The sky radiometer data, available at: http: //www.skynet-isdc.org/, last access: 28 May 2018.

Sugimoto, N., Nishizawa, T., Shimizu, A., Matsui, I., Jin, Y., Higurashi, A., Uno, I., Hara, Y., Yumimoto, K., and Kudo, R.: Continuous observations of atmospheric aerosols across East Asia, SPIE Newsroom, 2-5, https://doi.org/10.1117/2.1201510.006178, 2015.

Takamura, T. and Nakajima, T.: Overview of SKYNET and its activities, Opt. Pura Apl., 37, 3303-3308, 2004.

Tsunematsu, N., Sakai, T., and Nagai, T.: Strong capping inversion over the Tokyo metropolitan area associated with airborne Asian dust, Geophys. Res. Lett., 33, 1-5, https://doi.org/10.1029/2006GL026645, 2006.

Uchiyama, A., Yamazaki, A., Togawa, H., Asano, J., and Shi, G.: Single scattering albedo of aeolian dust as inferred from skydradiometer and in situ ground-based measurement, SOLA, 1, 209-212, https://doi.org/10.2151/sola.2005-054, 2005.

Uno, I., Eguchi, K., Yumimoto, K., Takemura, T., Shimizu, A., Uematsu, M., Liu, Z., Wang, Z., Hara, Y., and Sugimoto, N.: Asian dust transported one full circuit around the globe, Nat. Geosci., 2, 557-560, https://doi.org/10.1038/ngeo583, 2009.

Yu, H., Liu, S. C., and Dickinson, R. E.: Radiative effects of aerosols on the evolution of the atmospheric boundary layer, J. Geophys. Res., 107, 4142, https://doi.org/10.1029/2001JD000754, 2002. 